\title{
Teaching Reform on the Combination of Apparel Design and Fashion Process under Multi-perspectives
}

\author{
Xiaorong Deng \\ Jiangxi Institute of Fashion Technology, Nanchang, 330201, Jiangxi, China \\ 1056395964@qq.com
}

Keywords: Teaching reform; Apparel design; Fashion process; Combination; Curriculum

\begin{abstract}
Teaching method of fashion process calls for reforming the traditional instruction models, exposing students more practice and chances in an attempt to equip the students with the knowledge of essential spirit of fashion design. Starting with the combination of fashion process with the practical apparel design, trendy dress design and ethnic minorities costumes design, the article comes up with a challenge for traditional instruction approaches and designs to integrate a special teaching models, making a valuable attempt on integration of the techniques for style design, structure design, process design and so on.
\end{abstract}

\section{Introduction}

Now according to the current conditions of Chinese talent market, Chinese higher education has not functioned enough in cultivating pragmatic talent with strong creativity, there is a necessity in reforming class teaching for Chinese universities [1].With the development of the market economy, we should put the market-need as the guild and put the posts of the enterprises as the goal to cultivate the practical and technological talents that meet the needs of the market development requirement. This is the key of vocational education reform in this time. Therefore, the teaching contents and the teaching methods in colleges must be reformed continually to form the characteristics that conform to their development. Besides, we must change our education ideology, which is a long and lasting task, but we must adhere to it and make the rough step. In the current higher education reform, the innovation of teaching methods is essential and the task is very arduous. Teaching methods require changes in teaching philosophy to make the necessary reforms [2]. In this article, the teaching reform is discovered through the curriculum of apparel design and fashion process.

\section{The Status quo of Major Curriculum Practice Teaching}

With the development of modern economy and science technology, the need of the garment talents in the garment industry has become diversification. But our teaching methods and contents in fashion institutes does not change radically. The phenomenon is appearing: the garment theory knowledge learned in school is far behind the development reality of garment industry; the practice teaching design is not suitable to the vacant in the garment enterprises [3]. Here I sum up them as follows:

The characteristics of major curriculum and teaching method are not obvious. Major basic curriculum, major curriculum and internship teaching are arranged respectively. The curriculum and the curriculum are lack of effective communication. The combination of design and practice is not tightness. The guide to the practice curriculum is not enough, and the display of the teachers could not discover all students, so the arrangement form must also be reformed.

Besides, the major is narrow and could not catch up with the society and enterprise development. And some majors are old and not suitable to the cultivation of the talents. The connection of major and major, curriculum and curriculum are not built correctly. Especially some public curriculum, which does not play the corresponding role in the knowledge frame. Due to the factors and effects mentioned in above, the individual development and initiative of the students are limited greatly. Some students wrongly thought that fashion design asks for the special conception, masters the 
skills of drawing fashion pictures, draws the clothing effect diagram; you could become a designer if your clothing effect diagram is grasping one's heart and dazzling one's eyes which is a wrong thinking[4]. As you know, some students do not take much time in mastering the garment technology. They just could draw but not do. The phenomenon is very universal for many fashion major students. After graduation, many students enter the enterprises and pursuit the idealization. Others are the fashion stores. The empirical studies of fashion store projects demonstrate that the described system perspective offers a useful way of organizing fashion store designers' experiences from design processes [5]. The empirical studies of fashion store projects demonstrate that the described system perspective offers a useful way of organizing fashion store designers' experiences from design processes. The empirical studies of fashion store projects demonstrate that the described system perspective offers a useful way of organizing fashion store designers' experiences from design processes. They could draw the beautiful design sketches, but the acceptance ration is not high due to the style. Even some clothing effect diagrams are adopted by the market, the designers themselves could not make patterns, which lead to the difference of the sample clothing with the design effects. Advanced fashion designer from China Clothe Group criticized that Chinese costumes education pay much attention to the art and neglect the engineering technology, which is harmful to the development of garment industry. After investigation in France, an vice professor from Central Academy of Fine Arts said that more talents who master the overall style design, model and structure design and garment technology are needed and less fashion designers in abroad. Therefore, the cultivation of fashion designers is difficult to the development and the need of the society. In abroad, more and more clothing colleges emphasize the importance of fashion process teaching and enhance the practice for the students in this major [6]. Through the follow-up survey to the graduation, we discovered that most enterprises would like to select the students who had all-round abilities, especially well at making patterns, no matter Sino-foreign Joint Ventures, individual proprietorship or private enterprises. These students should assume the main responsibility and take charge of a department alone.

Therefore, fashion process teaching must change the traditional teaching method. The scientific and advanced garment knowledge should be taught to the students. What's more, an advanced structure design ideology should be built up in their brains. The students should be given more and more practice chances to make them know about the essence of fashion design. Through this way, we should achieve the goal: after designing the style, our students could know about the structure and make patterns, and integrate them into the fashion process. We adhere to the idea that combination of garment structure design and process design with style design, which is used to guide our practice teaching.

\section{Combination of Fashion Process and Practical Apparel Design}

The First Period. We define this time for the first term. Due to the freshmen students, they are poor at the garment major knowledge, only some students who have strong interest towards the fashion design know about a little on the garment industry. Therefore, we could arrange the curriculum as follows in the first term:

Basic Knowledge Structure. A. Master the necessary culture fundamental knowledge.

B. Master the basic theory knowledge of the form and about garments.

C. Master the knowledge of fashion process technology and apparel design.

D. Master the knowledge of the computer and some software

The Structure of Major Ability. A. Master the knowledge of fashion design basic theory and color composition, three- dimensional construction and planar formation

B. Master the ability of drawing simple garment structure patterns

C. Master the fundamental sewing process knowledge and the technology of simple making a certain part

Specific Teaching Contents. A Fundamental knowledge of making fashion design

Knowing about the common terms of the clothing which contains drawing instruments, garment type, drawing signs and so on. Master the method of the observing the body and measuring and 
the requirement of overweight and grading. Master the simple structure patterns and plate-making, such as skirts and women shirts. Learn to understand the books about the garment structure, and put the theory and practice together.

B. Fashion process

Teaching the knowledge of garment materials, fabrics and other materials, let the students know about the fabric structure, performance, characteristics and identify the method to distinguish the materials. Through the analysis of the physical garments, the combination of fabrics and style effects, to cultivate the students ability to use and choose the garment materials.

Through the simple sewing process teaching and a lot of practice, make the students master hand sewing process, machine sewing practice and fundamental sewing process.

The Second Period. We define this time for the second and the third term. Staring from the period, the contents of what the students learn enter major fundamental knowledge. We make the requirements as follows:

Fundamental Knowledge Structure. A. Master the drawing knowledge of the form and the human body with clothe

B. Master the fashion design, design principle and rule

C. Master some drawing software, such as CAD, COREDRAW, PS

D. Master the industry production management and fashion process

Major ability structure. A. Having the abilities of drawing clothing effect diagram and style patterns perfectly

B. Having the abilities of making patterns and choosing fabrics

C. Having the ability of making sample clothes

D. Having the abilities of popular trend consciousness and information analysis

E. Having the ability of using the computer to help design

\section{Specific Teaching Contents}

Fashion Design. Pay attention to the teaching of market survey of apparel fashion, design setting and the color match. Lead the students to know about the relationship of design and process correctly, and cultivate the students' market consciousness, merchandise consciousness and business ideology. Well, how to achieve these goals? The teachers could set the situation teaching, let the students participate the discussion and find the problems. Besides, the teachers could choose some homework of the students to explain. Through the practice, the students could make prepare for the learning of garment structure design.

Apparel Structure Design. About the apparel structure design, the teachers could choose the representative clothes. Taking the teaching method from the simple to the difficulty, through the garment prototype or ration distribution, let the students know about the process of making clothes. Well, maybe the learning process is lasting and difficulty, but only this way, could the students master the real ability of making clothes alone in the future. As you know, we permit some wrongs in practices, but always making wrongs are not permitted. The process design which is based on style and structure design is called the third design [7].

\section{Combination of Fashion Process and Popular Apparel Design}

During the fourth and the fifth term, the knowledge and ability structure of the students should be extended to the depth. In this period, we should enhance the student's application ability, popular fashion elements, the cultivation of creation consciousness. We require the students do market surveys largely, know about all kinds of styles and design characteristics. In class, the teachers should use the real case to explain the knowledge of what the students should master. For example, the First Lady: Peng Liyuan's wearing in different occasions is a good way to our teaching. Of course, the teachers themselves must master the fashion trend information, and encourage theirs students to participate different matches. In the match, obtaining the prize is not important, learn something and sum up experience is key, which is useful to the development in the future. Design 
and product development processes would be heavily dependent on digital technology; as a result, the role of technical design would grow in importance [8]. What is more, the teachers should make a breakthrough in teaching method and teaching contents. The students should know about the relationship of fashion process and apparel design correctly.

\section{Combination of Fashion Process and Minority National Apparel Design}

With the change of popular fashion trend ideology, minority national garments are becoming more and more popular. The designers are paying much attention to the minority national garments after they realize the importance of the minority national culture. However, how to combine the minority national garments with the modern garments elements? How to extract value from the minority national garments and carry forward? Which are all the direction of modern designers' thought and pursuit? Only by understanding, inheriting and enhancing the essence of ethnic costume, we can transfer it into the culture of modern fashion design, and gain enlightenment to integrate the culture of traditional ethnic dress with that of modern fashion [9].

\section{Summary}

In a word, we should stimulate and guide the interest and consciousness towards learning through selecting classic and successful case and rich teaching actives. Through the internship and practical teaching, we could change the ideology of the students that only doing beautiful designs are far from becoming the excellent designers. The students should make efforts in styles and patterns, more practice of sewing process. As the core and key of educational reform, class teaching reform directly relates to the quality of talent cultivation [10]. It shall fully develop the function of the orientation of the policies and stimulate activity and initiative of the teachers so as to promote class teaching reform and establish relevant management system guaranty. As the teachers, having the responsibility to remind the students of owning art cultivation is necessary. Besides, perfect designs are the combination of active design thinking, aesthetic art color and exquisite patterns and process. As an outstanding designer, he or she must remember in heart that the fashion style is the guide, and the fashion structure design is the continuity and the development of styles and model patterns.

\section{References}

[1] D. H. Ma: Problems in Class Teaching in Chinese Universities and Countermeasures in Teaching Reform [J]. Cross-Cultural Communication, 2015, Vol.11 (11), pp.113-117.

[2] F. Zhou: Reforms of University Teaching Methods [J]. Higher Education of Social Science, 2013, Vol.4 (1), pp.24-26.

[3] X. G. Liu: Brand Fashion Design [M], Shanghai, Donghua University Press, 2009. (in Chinese ) Roger Persson, Åse Marie Hansen and Anne Helene Garde: Can the job content questionnaire be used to assess structural and organizational properties of the work environment? International (b) Archives of Occupational and Environmental Health, 2012, Vol.85 (1), pp. $45-55$

[4] Anders Haug, Mia Borch Münster: Design Variables and Constraints in Fashion Store Design Processes[j]. International Journal of Retail \& Distribution Management, 2015, Vol.43 (9), pp.831-848.

[5] David Cárdenas Gonzalo: Influence of cushioning variables in the world of work and in the family on the probability of suffering stress [J], Safety and Health at Work, 2016.02.003.

[6] X. L. Ouyang: Fashion Process [M]. Higher Education Publication, 2000, pp. 264. 
[7] Eundeok Kim, Kim K.P. Johnson: Forecasting the US fashion industry with industry professionals - part 1: Materials and design[J]. Journal of Fashion Marketing and Management, 2009, Vol.13 (2).

[8] Y. Y. LI: A Study on the Application of Elements of Ethnic Dress in Modern Fashion Design [J]. Canadian Social Science, 2009, Vol.5 (2), pp.70-73.

[9] N. C. G. M. Donders, J. W. J. Gulden, J. W. Furer, B. Tax and E. W. Roscam Abbing : Work stress and health effects among university personnel[J]. International Archives of Occupational and Environmental Health, 2003, Vol.76 (8), pp. 605-613. 